\title{
PRODUTIVIDADE DE COLMOS E DE SACAROSE EM CANA-DE-AÇÚCAR EM FUNÇÃO DA INTERAÇÃO ENTRE CULTIVARES E MATURADORES
}

\section{PRODUCTIVITY OF STALK AND SUCROSE IN SUGARCANE IN RELATION TO CULTIVAR AND RIPENER INTERACTION}

\author{
Marcelo de Almeida SILVA ${ }^{1,2}$ \\ Glauber José Castro GAVA ${ }^{3}$ \\ Marina Maitto CAPUTO ${ }^{4}$ \\ Paula Francislaine SORRILLA ${ }^{5}$ \\ Silmara Cristiane BASSETTO ${ }^{6}$
}

\begin{abstract}
RESUMO
O emprego de reguladores vegetais como maturadores aplicados para antecipar a maturação da cana-de-açúcar é uma prática conhecida no setor sucroalcooleiro, entretanto as consequências na produtividade de diversas cultivares é pouco estudada. O objetivo deste trabalho foi avaliar a produtividade de colmos e de açúcar em cana-planta e o efeito residual sobre a cana-soca em função de diversos maturadores aplicados em cinco cultivares. $O$ delineamento experimental utilizado foi blocos ao acaso, em fatorial 5 x 6, constituídos de cinco cultivares (PO88-62, RB72454, RB845210, SP83-2847 e SP81-3250) e seis manejos de maturação (sulfometuron-metil; etefon; glifosato; etefon + glifosato; compostos de radicais carboxílicos orgânicos e testemunha), com três repetições, em Santa Maria da Serra, SP. Tanto na colheita, após a aplicação dos maturadores, quanto na colheita na soqueira seguinte foram avaliados os atributos: produtividade de colmos e de açúcar, produtividade média de colmos e de açúcar de duas colheitas, produtividade de colmos estimada para cinco cortes, queda de produtividade de colmos e de açúcar da primeira para a segunda colheita, teor de sacarose (pol\%) na cana e teor de sacarose média de duas colheitas. Não houve interação entre as cultivares e maturadores estudados para os atributos avaliados. O maturador sulfometuron-metil e a testemunha promoveram as menores quedas de produtividade do primeiro para o segundo corte. O maior ganho em teor de sacarose após a aplicação dos maturadores foi obtido com o emprego de sulfometuron-metil e etefon. Nenhum maturador afetou a produtividade de colmos e de açúcar.
\end{abstract}

Palavras-chave: Saccharum spp.; variedades; reguladores de crescimento; pol\%cana.

\begin{abstract}
The use of plant growth regulators as ripeners applied to anticipate the ripening of sugarcane is a well-known practice in the sugar and ethanol industry, however its consequences on the productivity of different cultivars is little studied. The objective of this work was to evaluate the stalk and sugar productivity in the plant cane and the residual effect on the ratoon in function of several ripeners applied in five cultivars. The experimental design used was the randomized blocks, in a 5 x 6 factorial arrangement, with five cultivars (PO88-62, RB72454, RB845210, SP83-2847 and SP81-3250) and six ripening managements (sulfomethuron-methyl; ethephon; glyphosate; ethephon + glyphosate; compounds of organic carboxylic radicals and control), with three replicates, in Santa Maria da Serra, SP. As on the harvest after the application of the ripeners as on the harvest in the following ratoon were evaluated the attributes: stalk and sugar productivity, average stalk and sugar productivity of two harvests, estimate stalk productivity for five harvests, decline stalk and sugar productivity from first to second harvest, sucrose (pol\%) in the cane and average sucrose of two harvests. There was not interaction among cultivars and ripeners for the attributes evaluated. The ripener sulfomethuron-methyl and the control promoted the smallest decline productivity from the first to the second harvest. The largest increase in sucrose after the ripeners application was obtained with sulfomethuron-methyl and ethephon. No ripener tested affected the stalk and sugar productivity.
\end{abstract}

Key-words: Saccharum spp.; varieties; plant growth regulators; pol\%cane.

\footnotetext{
${ }^{1}$ Engenheiro Agrônomo, Doutor em Agricultura, APTA Pólo Centro-Oeste - Agência Paulista de Tecnologia dos Agronegócios, Rodovia SP 304 (Jaú - Bariri), km 304, C.P. 66, 17201-970, Jaú, SP, Brasil. E-mail: marcelosilva@apta.sp.gov.br. Autor para correspondência.

${ }^{2}$ Bolsista de produtividade CNPq.

${ }^{3}$ Engenheiro Agrônomo, Doutor em Ciências, APTA Pólo Centro-Oeste - Agência Paulista de Tecnologia dos Agronegócios, Jaú, SP, Brasil. Email: ggava@apta.sp.gov.br

${ }^{4}$ Engenheira Agrônoma, Mestre em Fitotecnia, Universidade de São Paulo, Escola Superior de Agricultura Luiz de Queiroz, Piracicaba, SP,

Brasil. E-mail: mcaputo@esalq.usp.br

${ }^{5}$ Estudante de Biologia da Universidade Sagrado Coração/USC, Bauru, SP, Brasil. E-mail: paulasorrilla@yahoo.com.br

${ }^{6}$ Bióloga, APTA Pólo Centro-Oeste - Agência Paulista de Tecnologia dos Agronegócios, Jaú, SP, Brasil. E-mail: scbassetto@apta.sp.gov.br
} 
SILVA, M. A. et al. Produtividade de colmo e sacarose em...

\section{INTRODUÇÃO}

A cana-de-açúcar é uma espécie originária da Ásia, que se adaptou às condições brasileiras, tornando-se uma das culturas de maior importância econômica do país. Atualmente, o Brasil é o maior produtor mundial, sendo a cultura cultivada em todo seu território, com destaque para o estado de São Paulo, responsável por $58,4 \%$ da produção nacional (CONAB, 2008).

O ciclo de cultivo comercial da cana para produção de açúcar e etanol pode ser dividido em três fases fenológicas ou de desenvolvimento: estabelecimento da cultura, crescimento vegetativo e maturação (Rodrigues, 1995). A maturação da cana-de-açúcar ocorre naturalmente através dos estímulos ambientais, mas pode também ser realizada pela ação dos produtos reguladores de crescimento vegetal, definidos como maturadores, os quais têm por objetivo induzir o amadurecimento de plantas, causando, assim, a translocação e o máximo de acúmulo de sacarose na planta (Leite et al., 2009).

A aplicação de maturadores no sistema de produção da cana-de-açúcar tem sido adotada, principalmente, como uma técnica para a antecipação de sua maturação, porém também tem sido empregada como uma importante ferramenta de manejo para alcançar maiores produtividades de açúcar e etanol por tonelada de cana, além de proporcionar maior flexibilidade no gerenciamento da colheita (Caputo et al., 2008).

A época de aplicação desses produtos químicos, doses utilizadas, época de corte da matéria-prima são alguns dos fatores que podem influenciar na eficiência dos maturadores da canade-açúcar (Leite, 2005). Entretanto, as interações entre esses produtos e genótipos são pouco conhecidas (Caputo et al., 2008).

Apesar dos efeitos positivos, alguns reguladores vegetais utilizados como maturadores podem ter efeito prejudicial na soqueira seguinte. Leite \& Crusciol (2008) e Romero et al. (1998a, 2000) observaram redução na produção na soqueira posterior à aplicação de glifosato. De acordo com Romero et al. (2000), doses de glifosato superiores a $0,43 \mathrm{dm}^{3}$ ia $\mathrm{ha}^{-1}$ podem causar retardamento do processo de brotação e no crescimento da cultura no ciclo seguinte, além de causar amarelecimento severo e dessecamento das plantas. Por outro lado, Romero et al. (1998b) não encontraram efeito negativo na soqueira subsequente.

Pesquisas com outros agentes químicos têm demonstrado nenhuma interferência negativa ou até mesmo algum efeito positivo na rebrota e na produtividade da soqueira seguinte. Fernandes et al. (2002), Leite \& Crusciol (2008) e Silva et al. (2007) não observaram diferenças significativas em relação à testemunha com o emprego de sulfometuron-metil e, ainda, Silva et al. (2007) afirmaram que a aplicação de etefon promoveu maiores produtividades de colmos e de açúcar na cana-soca subsequente.
O presente estudo objetivou avaliar a produtividade de colmos e de açúcar em canaplanta e o efeito residual sobre a cana-soca em função de reguladores vegetais aplicados como maturadores em cinco cultivares.

\section{MATERIAL E MÉTODOS}

O experimento foi realizado na Fazenda Itaúna, no município de Santa Maria da Serra, SP, localizada na latitude de $22^{\circ} 33^{\prime} \mathrm{S}$ e longitude $48^{\circ}$ $10^{\prime} \mathrm{W}$, numa altitude de $495 \mathrm{~m}$ acima do nível do mar. O clima predominante da região é o Cfb (Köppen), clima com chuvas abundantes e bem distribuídas ao longo do ano, sendo o verão bastante fresco e úmido, temperatura média anual de $21,6^{\circ} \mathrm{C}$, umidade relativa média mensal de $70 \%$, com extremos de $99 \%$ em fevereiro e $19 \%$ em agosto. A média pluviométrica anual de $1.344 \mathrm{~mm}$. O solo da área experimental é classificado como Neossolo Quartzarênico (EMBRAPA, 1999).

A área experimental foi instalada em 25 de abril de 2002 e conduzida em cana-planta e primeira soca. O plantio foi realizado com uma adubação de $600 \mathrm{~kg} \mathrm{ha}^{-1}$ de adubo formulado 10 25-25 $\left(\mathrm{N}-\mathrm{P}_{2} \mathrm{O}_{5}-\mathrm{K}_{2} \mathrm{O}\right)$. Para o controle de pragas de solo foi aplicado no sulco, antes do plantio, $170 \mathrm{~g}$ p.c. de Fipronil $+2,5 \mathrm{dm}^{3}$ de Furadan em $50 \mathrm{dm}^{3} \mathrm{de}$ água na área útil. $\mathrm{Na}$ cana-soca, após 30 dias do primeiro corte, foram aplicados na entrelinha de cana $500 \mathrm{~kg} \mathrm{ha}^{-1}$ da fórmula 20-00-30 (N- $\left.\mathrm{P}_{2} \mathrm{O}_{5}-\mathrm{K}_{2} \mathrm{O}\right)$ para cultivo da soqueira. Para o controle de plantas daninhas foram aplicados após o plantio e o corte da soqueira $2,1 \mathrm{dm}^{3}$ de Ametrina $+2,1 \mathrm{dm}^{3}$ de Diuron $+1,0 \mathrm{dm}^{3}$ de MSMA em $300 \mathrm{dm}^{3}$ de água na área útil.

Utilizou-se o delineamento de blocos ao acaso, em esquema fatorial $5 \times 6$, constituídos pela combinação de cinco cultivares, P088-62, RB72454, RB845210, SP83-2847 e SP81-3250 e de seis manejos de condução da maturação, $15 \mathrm{~g}$ ia ha $^{-1}$ de sulfometuron-metil; $480 \mathrm{~g}$ ia ha ${ }^{-1}$ de etefon; $192 \mathrm{~g}$ ia ha-1 de glifosato; $240 \mathrm{~g}^{-1}$ ia ha ${ }^{-1}$ de etefon + $72 \mathrm{~g}$ ia ha ${ }^{-1}$ de glifosato; $1,0 \mathrm{dm}^{3} \mathrm{ha}^{-1}$ de compostos de radicais carboxílicos orgânicos (CC) e testemunha totalizando 30 tratamentos, com três repetições. As parcelas constituíram-se de nove sulcos de $10 \mathrm{~m}$ de comprimento, espaçados entre si por 1,0 m. Em cada parcela uma linha lateral foi desconsiderada por ocasião da aplicação dos produtos maturadores, para servir de bordadura entre as parcelas. A parcela ficou então com área útil de oito linhas de $10 \mathrm{~m}$.

A aplicação dos maturadores ocorreu em datas recomendadas para cada produto químico, conforme as especificações dos fabricantes. Assim, o sulfometuron-metil foi aplicado no dia 07 de maio de 2003 (65 dias antes da colheita - DAC), etefon no dia 28 de abril de 2003 (74 DAC), glifosato no dia 27 de maio de 2003 (45 DAC), etefon + glifosato no dia 17 de maio de 2003 (55 DAC) e CC foi aplicado em 27 de maio de 2003 (45 DAC). Todas as aplicações foram feitas com equipamento pressurizado por cilindro de $\mathrm{CO}_{2}$ comprimido, conectado a uma garrafa de PVC, com a calda 
SILVA, M. A. et al. Produtividade de colmo e sacarose em...

preparada, ligada a seis bicos AXI 11002 , sustentados por uma barra de $6,0 \mathrm{~m}$ em forma de $U$ invertido, suspensa por duas pessoas, caminhando no mesmo ritmo. Uma das pessoas levava também a garrafa com a calda do produto químico, bem como, a alavanca para acionar a aspersão ou interrompê-la. A pressão de trabalho foi de 0,35 MPa para a vazão de $100 \mathrm{dm}^{3} \mathrm{ha}^{-1}$.

O primeiro corte da área foi feito em $11 \mathrm{de}$ julho de 2003, quando as plantas apresentavam 14 meses e meio de idade. A segunda colheita ocorreu em 25 de junho de 2004, aos 11 meses e meio de idade.

Em cada colheita foram obtidas as características: teor de sacarose na cana, produtividade de colmos e produtividade de açúcar.

Para obtenção do teor de sacarose (pol\%) da cana foi colhido de cada parcela um feixe de 10 colmos industriais, retirados seguidamente $e$ aleatoriamente nas oito linhas, consideradas como parcela útil e, posteriormente, os feixes foram encaminhados ao laboratório.

Para avaliação da produtividade de colmos (toneladas de cana por hectare - $\mathrm{TCH}$ ) foi feita a obtenção da massa $(\mathrm{kg})$ da parcela por meio de balança tipo célula de carga graduada em $200 \mathrm{~g}$. Foram somadas à massa final as massas de cada feixe retirado para avaliação da maturação. A massa determinada em $80 \mathrm{~m}^{2}$ foi extrapolada para a obtenção da produtividade em $\mathrm{t} \mathrm{ha}^{-1}$.

Para o cálculo de produtividade média de cana estimada para cinco cortes ( $\mathrm{TCH} 5)$ foram usados os dados de TCH de cada colheita e aplicados na fórmula de Braga Junior (1994):

$\mathrm{TCH} 5=(\mathrm{TCH} 1+3,5 \times \mathrm{TCH} 2) / 5$

onde:

$\mathrm{TCH} 1$ é o valor da produtividade no primeiro corte e

$\mathrm{TCH} 2$ é o valor da produtividade no segundo corte.

A produtividade de açúcar (TPH) foi obtida por meio do produto entre a $\mathrm{TCH}$ e a pol\%cana correspondente de cada parcela, dividido por cem.

Obteve-se a queda de produtividade $(\mathrm{Q} \%)$, tanto para colmos (QTCH) quanto para açúcar (QTPH), do $1^{\circ}$ ao $2^{\circ}$ corte, empregando-se a expressão adaptada de Alvarez et al. (1987):

$\mathrm{Qx} \%=[(\mathrm{PI}-\mathrm{Px}) / \mathrm{PI}] \times 100$

onde:

Px representa a produção do corte considerado e

P1 a produção de cana-planta.

Os resultados obtidos das avaliações experimentais foram submetidos à análise de variância utilizando o teste $\mathrm{F}$ a $95 \%$. Posteriormente, para as causas de variação significativas, foi aplicado o teste Scott-Knott $(P<$ $0,05)$ para agrupamento das médias.

\section{RESULTADOS E DISCUSSÃO}

As condições climáticas observadas no local do experimento foram favoráveis para o desenvolvimento da cultura tanto em cana-planta quanto em cana-soca durante os estádios de grande crescimento, com temperaturas médias máximas e mínimas e precipitação elevadas nos meses de outubro de 2002 a abril de 2003 e de outubro de 2003 a abril de 2004 (Rodrigues, 1995). Da mesma forma, o clima foi favorável à maturação da cana-de-açúcar no período de repouso fisiológico (Rodrigues, 1995), com baixas temperaturas e pouca precipitação nos meses de maio a setembro de 2003 e de maio a junho de 2004 (Figura 1).

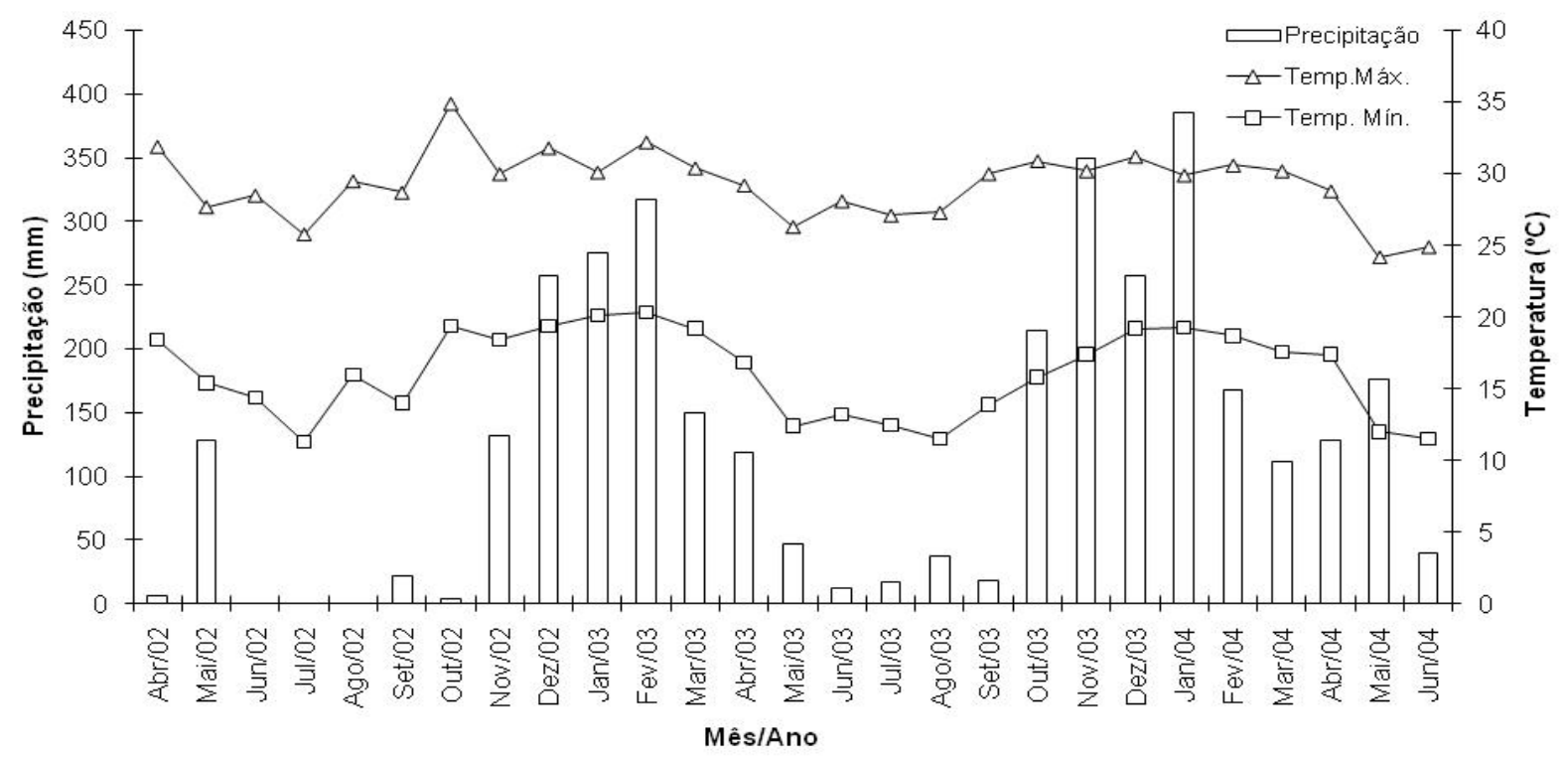

FIGURA 1 - Temperaturas médias máximas e mínimas mensais $\left({ }^{\circ} \mathrm{C}\right)$ e precipitação total (mm), por mês, observadas em Santa Maria da Serra, SP, nas safras 2002/2003 e 2003/2004. 
SILVA, M. A. et al. Produtividade de colmo e sacarose em...

Em termos de produtividade de colmos, a análise de variância indicou a significância das causas de variação relacionadas às cultivares relativas à produtividade de colmos no primeiro corte (TCH1), produtividade de colmos no segundo corte (TCH2), produtividade de colmos média (TCHM), estimativa de produtividade para cinco cortes $(\mathrm{ETCH} 5)$ e para o índice que quantifica a queda de produtividade do primeiro para o segundo corte (QTCH) (Tabela 1). Para maturadores foi encontrada significância apenas para QTCH. No entanto, nenhuma interação significativa foi encontrada entre os tratamentos para esses atributos.

TABELA 1 - Produtividade de colmos, em tonelada de colmos por hectare, na primeira colheita (TCH1) e na segunda colheita ( $\mathrm{TCH} 2)$; produtividade de colmos, média de duas colheitas (TCHM); estimativa de produtividade de colmos para cinco colheitas $(\mathrm{ETCH} 5)$ e queda de produtividade de colmos da primeira para a segunda colheita $(\mathrm{QTCH})$, em porcentagem, em função de cultivares e maturadores $^{(1)}$.

\begin{tabular}{|c|c|c|c|c|c|c|}
\hline Tratamentos & & TCH1 & $\overline{\mathrm{TCH} 2}$ & TCHM & ETCH5 & QTCH\% \\
\hline \multirow{5}{*}{ Cultivar } & P088-62 & $137,2 a$ & $98,1 a$ & $117,7 a$ & $96,1 a$ & $28,4 b$ \\
\hline & RB72454 & $123,6 c$ & $77,7 \mathrm{~b}$ & $100,7 b$ & $79,1 b$ & $37,2 a$ \\
\hline & RB845210 & $117,4 d$ & $82,3 b$ & $99,9 b$ & $81,1 \mathrm{~b}$ & $29,7 \mathrm{~b}$ \\
\hline & SP83-2847 & $129,5 b$ & $103,5 a$ & $116,5 a$ & $98,4 a$ & $20,0 c$ \\
\hline & SP81-3250 & $112,1 \mathrm{e}$ & $74,6 \mathrm{~b}$ & $93,4 \mathrm{c}$ & $74,6 \mathrm{c}$ & $33,3 a$ \\
\hline \multirow{6}{*}{ Maturador } & Sulfometuron-metil & $122,5 a$ & $88,9 a$ & $105,7 a$ & $86,8 a$ & $27,6 \mathrm{~b}$ \\
\hline & Etefon & $125,4 a$ & $88,4 a$ & $106,9 a$ & $86,9 a$ & $29,3 a$ \\
\hline & Glifosato & $124,0 a$ & $86,4 a$ & $105,2 a$ & $85,3 a$ & $30,6 a$ \\
\hline & Etefon + Glifosato & $124,1 a$ & $82,9 a$ & $103,5 a$ & $82,9 a$ & $33,2 a$ \\
\hline & $\mathrm{CC}^{2}$ & $124,8 a$ & $83,8 a$ & $104,3 a$ & $83,6 a$ & $33,1 a$ \\
\hline & Testemunha & $123,1 a$ & $93,0 a$ & $108,1 a$ & $89,8 a$ & $24,6 \mathrm{~b}$ \\
\hline \multirow{4}{*}{$\begin{array}{l}\text { Quadrados } \\
\text { Médios }\end{array}$} & Bloco & $42457,9^{\star \star}$ & $697,8^{\text {ns }}$ & $13160,3^{\text {ns }}$ & $3368,2^{\text {ns }}$ & $9573,3^{\text {ns }}$ \\
\hline & Cultivar (C) & $175465,6^{* *}$ & ${ }_{*}^{2960074,7^{*}}$ & $212261,5^{* *}$ & $204946,0^{* *}$ & $74070,7^{* \star}$ \\
\hline & Maturador (M) & $1680,9^{\text {ns }}$ & $20675,9^{\text {ns }}$ & $4184,0^{\text {ns }}$ & $9411,5^{\mathrm{ns}}$ & $16568,4^{*}$ \\
\hline & $C \times M$ & $1807,2^{\text {ns }}$ & $6320,5^{\text {ns }}$ & $2009,0^{\text {ns }}$ & $3156,5^{\text {ns }}$ & $4813,0^{\text {ns }}$ \\
\hline & C.V. (\%) & 5,4 & 12,0 & 6,9 & 9,3 & 10,8 \\
\hline
\end{tabular}

(1) Médias não seguidas de mesma letra na coluna dentro de cada atributo (cultivar e maturador) diferem estatisticamente pelo teste Scott-Knott a $5 \%$ de probabilidade de erro; ns, *, ** não significativo, significativo a $5 \%$ e a $1 \%$, respectivamente.

(2) Compostos de radicais carboxílicos orgânicos.

A maior produtividade de colmos no primeiro corte foi observada para a cultivar P088-62 que superou significativamente as demais cultivares (Tabela 1). Todavia, para TCH2, TCHM e ETCH5, a cultivar SP83-2847 igualou-se estatisticamente ao P088-62 como os de maiores médias. Quanto à manutenção da produtividade ao longo do primeiro para o segundo corte (QTCH), o menor valor significa o melhor resultado por representar a menor queda e, portanto, a cultivar SP83-2847 superou as demais. As diferenças encontradas entre as cultivares são reflexos da constituição genética inerente a cada uma, assim, não sendo atribuída nenhuma resposta aos maturadores, tratamentos, mas demonstra 0 potencial produtivo e de longevidade das cultivares PO88-62 e SP83-2847, características necessárias para a busca da economicidade desta atividade agrícola (Silva et al., 2010).

Quanto ao efeito dos maturadores nos 
SILVA, M. A. et al. Produtividade de colmo e sacarose em...

atributos de produtividade de colmos (Tabela 1), observou-se diferença significativa apenas no atributo QTCH em que, na média geral, o maturador sulfometuron-metil igualou-se à testemunha $e$ tiveram os menores valores de queda de produtividade do primeiro para o segundo corte, variando de 24,6 a $27,6 \%$, enquanto os demais maturadores promoveram maiores efeitos negativos na soqueira seguinte, com queda de produtividade na ordem de $31,6 \%$ em média. Esses resultados corroboram em parte com os encontrados por Silva et al. (2007), pois esses autores observaram também que sulfometuron-metil não declinou a produtividade em relação à testemunha na soqueira seguinte, por outro lado obtiveram produtividade maior do que a testemunha quando o etefon foi empregado. Leite \& Crusciol (2008) observaram reduções significativas na soqueira do ano seguinte nos tratamentos com glifosato e na associação glifosato + CC. As cultivares estudadas neste trabalho são diferentes aos utilizados por Silva et al. (2007) e por Leite \& Crusciol (2008), sendo já constatada por outros autores a existência de diferentes respostas relacionadas a genótipos (Dusky et al., 1985; Subiros, 1990; Caputo et al., 2007; Silva et al., 2007) e, provavelmente, as cultivares deste trabalho sejam pouco responsivas a estes produtos.
$\mathrm{Na}$ Tabela 2 são apresentados os valores de concentração de sacarose na cana (pol\%) na primeira e na segunda colheita e a média das duas colheitas. Verificou-se efeito significativo para cultivar nesses três atributos e para maturadores apenas na pol\%cana do primeiro corte e na pol\% cana média dos dois cortes. Não houve interação significativa entre cultivar e maturador para os atributos de qualidade tecnológica, provavelmente em razão dessa interação ser afetada por épocas de amostragem (Dusky et al., 1985). Na primeira colheita, as cultivares RB845210 e SP81-3250 tiveram os maiores valores significativos de pol\% cana; e na segunda colheita e na média de dois cortes, a P088-62 fez parte desse grupo das maiores médias de pol\%cana. Por outro lado, na cultivar SP83-2847 foi observada a menor média para esse atributo na média e nas duas colheitas. Resultados justificados pelas diferenças genéticas entre as cultivares, que as classificam em diferentes épocas de colheita no decorrer da safra, visto que as cultivares P088-62 e RB845210 são consideradas precoces (Caputo et al., 2008; Daros et al., 2001, respectivamente) e SP81-3250 é considerada média (COPERSUCAR, 1993). Por outro lado a SP83-2847 é classificada como tardia (COPERSUCAR, 1999).

TABELA 2 - Concentração de sacarose na cana, em porcentagem de pol, na primeira colheita (Pol\%1C); na segunda colheita (Pol\%2C) e média de duas colheitas (Pol\%M), em função de cultivares e maturadores ${ }^{(1)}$.

\begin{tabular}{|c|c|c|c|c|}
\hline Tratamentos & & Pol\%1C & Pol\%2C & Pol\%M \\
\hline \multirow{5}{*}{ Cultivar } & PO88-62 & $15,2 b$ & $14,6 a$ & $14,9 a$ \\
\hline & RB72454 & $14,6 \mathrm{c}$ & $13,7 b$ & $14,2 b$ \\
\hline & RB845210 & $15,6 a$ & $14,5 a$ & $15,0 a$ \\
\hline & SP83-2847 & $13,2 d$ & $13,2 \mathrm{c}$ & $13,2 \mathrm{c}$ \\
\hline & SP81-3250 & $15,6 a$ & $14,6 a$ & $15,1 \mathrm{a}$ \\
\hline \multirow{6}{*}{ Maturador } & Sulfometuron-metil & $15,3 a$ & $14,3 a$ & $14,8 a$ \\
\hline & Etefon & $15,0 a$ & $14,0 a$ & $14,5 b$ \\
\hline & Glifosato & $14,7 b$ & $14,0 a$ & $14,3 b$ \\
\hline & Etefon + Glifosato & $14,7 \mathrm{~b}$ & $14,2 a$ & $14,5 b$ \\
\hline & $C C^{2}$ & $14,7 \mathrm{~b}$ & $14,2 a$ & $14,5 b$ \\
\hline & Testemunha & $14,7 b$ & $13,9 a$ & $14,3 b$ \\
\hline \multirow{5}{*}{ Quadrados Médio } & Bloco & $201,1^{* \star}$ & $13,4^{\text {ns }}$ & $78,1^{* *}$ \\
\hline & Cultivar (C) & $1830,8^{* *}$ & $710,4^{* *}$ & $1169,9^{* *}$ \\
\hline & Maturador (M) & $81,2^{*}$ & $46,9^{\text {ns }}$ & $41,2^{*}$ \\
\hline & $\mathrm{C} \times \mathrm{M}$ & $40,3^{\text {ns }}$ & $28,1^{\mathrm{ns}}$ & $14,7^{\mathrm{ns}}$ \\
\hline & C.V. (\%) & 3,4 & 3,7 & 2,6 \\
\hline
\end{tabular}

\footnotetext{
(1) Médias não seguidas de mesma letra na coluna dentro de cada atributo (cultivar e maturador) diferem estatisticamente pelo teste Scott-Knott a $5 \%$ de probabilidade de erro; ns, * ${ }^{* *}$ não significativo, significativo a $5 \%$ e a $1 \%$, respectivamente.

(2) Compostos de radicais carboxílicos orgânicos.
} 
SILVA, M. A. et al. Produtividade de colmo e sacarose em...

Os maturadores sulfometuron-metil e etefon promoveram ganhos na pol\%cana, após a aplicação no primeiro corte, em que seus valores médios superaram significativamente os demais tratamentos, oferecendo ganhos de 0,6 e 0,3 na pol\%cana, respectivamente (Tabela 2). Esses resultados conferem com os de Caputo et al. (2007) que também conseguiram ganhos significativos com o emprego desses dois maturadores em diversos genótipos. Subiros (1990) identificou resposta diferenciada de cultivares à aplicação de glifosate, em razão das três cultivares avaliadas, observando que apenas a Q-68 apresentou diferença significativa para pol\%cana aos 45 dias após a aplicação. Não houve efeito residual de nenhum dos produtos em termos de maturação para o segundo corte, entretanto o maior valor médio absoluto verificado para sulfometuron-metil no segundo corte contribuiu para que esse tratamento proporcionasse maior pol\%cana média em dois cortes, diferindo significativamente dos demais tratamentos. Portanto, independente da cultivar, o maturador sulfometuron-metil trouxe maiores ganhos em sacarose em duas safras, sendo indicativo de melhor manejo para esse fim.

A produtividade de açúcar (TPH) está apresentada na Tabela 3 onde é observado efeito significativo das causas de variação apenas para cultivar. Neste caso, a PO88-62 foi significativamente superior que as demais cultivares no primeiro corte e na média de duas colheitas, enquanto na segunda colheita, a SP83-2847 igualou-se significativamente à PO88-62 e, assim, ambas superaram os demais tratamentos. Quanto à queda de produtividade de açúcar (QTPH), a cultivar SP83-2847 teve a menor média e, portanto, foi a que apresentou menor declínio desse atributo do primeiro para o segundo corte. Esses resultados correspondem muito aos encontrados para $\mathrm{TCH}$ (Tabela 1), devido a forte relação entre esses dois atributos (Caputo et al., 2007).

TABELA 3 - Produtividade de açúcar, em tonelada de pol por hectare, na primeira colheita (TPH1) e na segunda colheita (TPH2); produtividade de açúcar média de duas colheitas (TPHM) e queda de produtividade de açúcar da primeira para a segunda colheita (QTPH), em porcentagem, em função de cultivares e maturadores ${ }^{(1)}$.

\begin{tabular}{|c|c|c|c|c|c|}
\hline Tratamentos & & TPH 1C & TPH 2C & TPH M & QTPH\% \\
\hline \multirow{5}{*}{ Cultivar } & PO88-62 & $20,9 a$ & $14,3 a$ & $17,6 a$ & $31,4 b$ \\
\hline & RB72454 & $18,1 b$ & $10,6 c$ & $14,3 \mathrm{c}$ & $41,4 a$ \\
\hline & RB845210 & $18,3 b$ & $11,9 b$ & $15,1 b$ & $35,0 b$ \\
\hline & SP83-2847 & $17,1 \mathrm{c}$ & $13,6 a$ & $15,4 b$ & $20,9 c$ \\
\hline & SP81-3250 & $17,5 c$ & $10,9 c$ & $14,2 \mathrm{c}$ & $37,8 a$ \\
\hline \multirow{6}{*}{ Maturador } & Sulfometuron-metil & $18,7 a$ & $12,7 a$ & $15,7 a$ & $32,2 a$ \\
\hline & Etefon & $18,8 a$ & $12,3 a$ & $15,6 a$ & $34,3 a$ \\
\hline & Glifosato & $18,2 a$ & $12,0 \mathrm{a}$ & $15,1 a$ & $33,1 \mathrm{a}$ \\
\hline & Etefon + Glifosato & $18,2 a$ & $11,8 a$ & $15,0 a$ & $35,2 a$ \\
\hline & $\mathrm{CC}^{2}$ & $18,3 a$ & $11,9 a$ & $15,1 a$ & $34,8 a$ \\
\hline & Testemunha & $18,1 \mathrm{a}$ & $12,8 a$ & $15,4 a$ & $28,9 a$ \\
\hline \multirow{4}{*}{$\begin{array}{l}\text { Quadrados } \\
\text { Médios }\end{array}$} & Bloco & $353,1^{\mathrm{ns}}$ & $528,1^{\text {ns }}$ & $110,3^{\text {ns }}$ & $3328,5^{\text {ns }}$ \\
\hline & Cultivar (C) & $3988,5^{\star *}$ & $4929,9^{* *}$ & $3409,9^{* *}$ & $122408,4^{\star *}$ \\
\hline & Maturador (M) & $119,5^{\mathrm{ns}}$ & $252,1^{\mathrm{ns}}$ & $107,5^{\mathrm{ns}}$ & $8376,2^{\text {ns }}$ \\
\hline & $C \times M$ & $105,7^{\mathrm{ns}}$ & $88,4^{\mathrm{ns}}$ & $48,5^{\mathrm{ns}}$ & $5055,0^{\mathrm{ns}}$ \\
\hline & C.V. (\%) & 6,3 & 11,5 & 6,6 & 12,1 \\
\hline
\end{tabular}

\footnotetext{
(1) Médias não seguidas de mesma letra na coluna dentro de cada atributo (cultivar e maturador) diferem estatisticamente pelo teste Scott-Knott a $5 \%$ de probabilidade de erro; ns, ${ }^{*},{ }^{* *}$ não significativo, significativo a $5 \%$ e a $1 \%$, respectivamente. (2) Compostos de radicais carboxílicos orgânicos.
} 
SILVA, M. A. et al. Produtividade de colmo e sacarose em...

Nenhum efeito significativo foi observado para maturador e para a interação entre esse tratamento e cultivar (Tabela 3), discordando de Caputo et al. (2007) que encontraram respostas interativas entre sete genótipos e os maturadores etefon e sulfometuron-metil. Provavelmente, essa falta de resposta deve-se ao fato da TPH estar em função do produto entre $\mathrm{TCH}$ e pol\%cana e devido a maior TCH de uma determinada cultivar não estar relacionada à maior pol\%cana, os efeitos associativos podem ter sido anulados.

\section{CONCLUSÕES}

Não houve interação entre as cultivares e os maturadores estudados para os atributos avaliados.

O maturador sulfometuron-metil e a testemunha promoveram as menores quedas de produtividade do primeiro para o segundo corte. Mas nenhum maturador promoveu redução na estimativa de produtividade para cinco cortes.
O maior ganho em teor de sacarose após a aplicação dos maturadores foi obtido com o emprego de sulfometuron-metil e etefon.

Nenhum maturador afetou a produtividade de colmos e de açúcar.

\section{AGRADECIMENTOS}

Ao Grupo COSAN - Usina da Barra pelo fornecimento da área experimental e pela assistência em campo. Ao Conselho Nacional de Desenvolvimento Científico e Tecnológico (CNPq) pela concessão de bolsa de produtividade em pesquisa a Marcelo de Almeida Silva.

\section{CONFLITOS DE INTERESSES}

O presente trabalho não apresenta conflitos de interesses que sejam do conhecimento dos autores, e não há relação de vínculo profissional ou de consultoria dos autores aos fabricantes dos produtos testados.

\section{REFERÊNCIAS}

1. ALVAREZ, R. et al. Melhoramento genético da cana-de-açúcar: avaliação de clones provenientes de hibridações efetuadas em 1965. Bragantia, v. 46, n. 1, p. 121-126, 1987.

2. BRAGA JÚNIOR, R.L.C. Equação para estimativa da produtividade média de cinco cortes a partir dos dois primeiros cortes. In: SEMINÁRIO DE TECNOLOGIA AGRONÔMICA, 6.,1994, Piracicaba. Anais... Piracicaba: COPERSUCAR, 1994. p.131-136.

3. CAPUTO, M.M. et al. Resposta de genótipos de cana-de-açúcar à aplicação de indutores de maturação. Bragantia, v. 67 , n. 1, p. 15-23, 2008.

4. CAPUTO, M.M. et al. Acúmulo de sacarose, produtividade e florescimento de cana-de-açúcar sob reguladores vegetais Interciencia, v. 32, n. 12, p. 834-840, 2007.

5. CONAB. Perfil do setor do açúcar e do álcool no Brasil. Brasília: Companhia acional de Abastecimento, 2008. 76 p.

6. COPERSUCAR. Quarta geração de variedades de cana-de-açúcar Copersucar. Piracicaba: Centro de Tecnologia Copersucar, 1993, 16 p. (Boletim Técnico Copersucar, Edição Especial).

7. COPERSUCAR. Sétima geração de variedades de cana-de-açúcar Copersucar. Piracicaba: Centro de Tecnologia Copersucar, 1999, 32 p. (Boletim Técnico Copersucar, Edição Especial).

8. DAROS, E. et al. Novas variedades de cana-de-açúcar. Curitiba: RIDESA, 2001, 28 p. (Boletim Técnico)

9. DUSKY, J.A. et al. Response of eight sugarcane cultivars to glyphosine and glyphosate riperners. Journal of Plant Growth Regulation, v. 4, n. 1-4, p. 225-235, 1985.

10. EMBRAPA. Sistema brasileiro de classificação dos solos. Rio de Janeiro: EMBRAPA/CNPS, 1999. 412 p.

11. FERNANDES, A.C.; STUPIELLO, J.P.; UCHOA, P.E.A. Utilização do curavial para melhoria da qualidade da cana-deaçúcar. STAB Açúcar, Álcool e Subprodutos, v. 20, n. 4, p. 43-46, 2002.

12. LEITE, G.H.P. Maturação induzida, alterações fisiológicas, produtividade e qualidade tecnológica da cana-deaçúcar (Saccharum officinarum L.). 2005. 141 f. Dissertação (Mestrado em Produção Vegetal). Curso de Pós-Graduação em Agricultura, setor de Agricultura e Melhoramento Vegetal, Faculdade de Ciências Agronômicas, UNESP, Botucatu, 2005.

13. LEITE, G.H.P.; CRUSCIOL, C.A.C. Reguladores vegetais no desenvolvimento e produtividade da cana-de-açúcar. Pesquisa Agropecuária Brasileira, v. 43, n. 8, p. 995-1001, 2008

14. LEITE, G.H.P. et al. Qualidade tecnológica da cana-de-açúcar em função da aplicação de maturadores em meio de safra. Bragantia, v. 68, n. 2, p. 527-534, 2009.

15. RODRIGUES, J.D. Fisiologia da cana-de-açúcar. Botucatu: Universidade Estadual Paulista - UNESP, 1995. $69 \mathrm{p}$.

16. ROMERO, E.R.; SCANDALIARIS, J.; RUFINO, M. Respuesta de la caña de azúcar al madurativo glifosato. II. Otros efectos del madurador y recomendaciones de manejo. Avance Agroindustrial, v. 19, n. 74, p. 4-7, 1998a.

17. ROMERO, E.R. et al. Respuesta de la caña de azúcar a la aplicación de glifosato como madurador. I. Efectos en la calidad fabril e influência de los factores ambientales. Avance Agroindustrial, v. 19, n. 74, p. 7-10, 1998b.

18. ROMERO, E.R. et al. Actualización de las recomendaciones de manejo de glifosato como madurador de la caña de azúcar. Avance Agroindustrial, v. 21, n. 22, p. 22-27, 2000.

19. SILVA, M.A.; CATO, S.C.; COSTA, A.G.F. Produtividade e qualidade tecnológica da soqueira de cana-de-açúcar submetida à aplicação de biorregulador e fertilizantes líquidos. Ciência Rural, v. 40, n. 4, p. 774-780, 2010.

20. SILVA, M.A. et al. Uso de reguladores de crescimento como potencializadores do perfilhamento e da produtividade em cana-soca. Bragantia, v. 66, n. 4, p. 545-552, 2007.

21. SUBIROS, J.F. Efecto de la aplicación glifosato como madurador en tres cultivares de caña de azúcar. Turrialba, v. 40 , n. 4, p.527-534, 1990.

Recebido em 01/02/2010

Aceito em 30/07/2010 
